\title{
Attribution of Recent Temperature Changes in the Australian Region
}

\author{
DAVID J. KAROLY \\ School of Meteorology, University of Oklahoma, Norman, Oklahoma \\ KARL BRAGANZA \\ School of Mathematical Sciences, Monash University, Clayton, Victoria, Australia
}

(Manuscript received 20 January 2004, in final form 10 May 2004)

\begin{abstract}
Variations of Australian-average mean temperature and diurnal temperature range over the twentieth century are investigated. The observed interannual variability of both is simulated reasonably well by a number of climate models, but they do not simulate the observed relationship between the two. Comparison of the observed warming and reduction in diurnal temperature range with climate model simulations shows that Australian temperature changes over the twentieth century were very unlikely to be due to natural climate variations alone. It is likely that there has been a significant contribution to the observed warming during the second half of the century from increasing atmospheric greenhouse gases and sulfate aerosols.
\end{abstract}

\section{Introduction}

The Synthesis Report of the Intergovernmental Panel on Climate Change (IPCC) Third Assessment (Watson et al. 2001) concluded that one of the key uncertainties regarding attribution of climate change was "relating regional trends to anthropogenic climate change." Most studies of the possible causes of twentieth-century climate change have concentrated on global-scale patterns of temperature change (Mitchell et al. 2001). This is primarily because the magnitude of natural climate variability relative to any greenhouse-gasinduced climate change signal increases as the spatial scale of consideration is reduced (Stott and Tett 1998). Recently, it has been shown that an anthropogenic climate change signal is detectable in large regions using surface temperature changes over the twentieth century (Karoly et al. 2003; Stott 2003; Zwiers and Zhang 2003). Stott (2003) used simulations with the Third Hadley Centre Coupled Ocean-Atmosphere General Circulation Model (HadCM3) to show that most of the observed warming over the last 50 years in six separate regions of the globe, including North America, Eurasia, and Australia, was likely to be due to the increase in greenhouse gases in the atmosphere. In a similar study, Zwiers and Zhang (2003) used the Canadian climate

Corresponding author address: Dr. David Karoly, School of Meteorology, University of Oklahoma, 100 E. Boyd St., Norman, OK 73019.

E-mail: dkaroly@ou.edu model to assess the detectability of an anthropogenic climate change signal at different scales and showed that such a signal could be detected in the observed warming in North America and Eurasia over the twentieth century. While these two studies used the optimal fingerprint method, Karoly et al. (2003) identified a significant human influence in recent North American climate change using several simple indices of surface temperature variations.

There has been a marked increase in observed Australian area-average mean temperature and a decrease in diurnal temperature range during the twentieth century, with most of these changes over the last 50 years (Plummer et al. 1995; Torok and Nicholls 1996; DellaMarta et al. 2004). Nicholls (2003) has examined the relationship between observed Australian-average maximum temperature and rainfall variations and concluded that the increase in maximum temperatures is not associated with rainfall variations and is not likely to be due to natural climate variations alone.

Here, we investigate the causes of these changes in Australian-average temperatures by comparing simulations performed by six different global climate models with observed climate variations. Australia is a good place to test regional climate change attribution as it has a relatively good observational network for most of the twentieth century and it has coherent large-scale climate variations over much of the country. The climate model simulations represent the natural internal variability of climate as well as its response to human influences, such as increases in atmospheric greenhouse 
gases and sulfate aerosols. Natural external influences (changes in solar irradiance and volcanic aerosols) are also included in some simulations. This is a significant extension of other regional climate change attribution studies as we use the results from six different models and consider both mean temperature and diurnal temperature range for a smaller region than most other studies. Stott (2003) considered Australian temperature changes and concluded "it is not possible to reliably attribute Australian temperature changes" in his analysis because "the level of agreement between observed Australian temperature changes and anthropogenic forced model simulations was not as good as for other regions." Here, we further investigate the attribution of recent Australian temperature changes using a different approach from Stott (2003), a number of different climate models, and a slightly different observational dataset.

\section{Data}

We use observed Australian-average temperature anomaly data from the Australian Bureau of Meteorology for the period 1910-2002 (online at http:// www.bom.gov.au/climate/change/amtemp.shtml). These have been calculated using maximum and minimum temperature data from approximately 130 nonurban observing stations throughout the country. These stations are part of a high-quality temperature dataset, where adjustments have been made for discontinuities caused by changes in instrumentation and site location (Torok and Nicholls 1996; Della-Marta et al. 2004). We consider annual-average anomalies of mean temperature (mean), maximum temperature (max), minimum temperature $(\mathrm{min})$, and diurnal temperature range (DTR). Since DTR is the difference between the maximum and minimum temperatures, it is expected to contain some information independent from mean temperature. The Bureau of Meteorology high-quality dataset shows slightly lower temperatures in the early twentieth century and a slightly larger warming trend in the first part of the twentieth century than the Jones et al. (1999) dataset used by Stott (2003). This arises because of the corrections of maximum temperatures for exposure to solar radiation at some Australian sites that did not use standard Stephenson screens in the early part of the record (Della-Marta et al. 2004).

The observed climate variations in the twentieth century are compared to simulations with six global coupled ocean-atmosphere climate models from

- Commonwealth Scientific and Industrial Research Organization (CSIRO), Australia [CSIRO Atmospheric Research Mark 2b (Mk2)];

- Geophysical Fluid Dynamics Laboratory (GFDL), United States (GFDL R30 model);

- Hadley Centre, United Kingdom [Second Hadley Center Coupled Ocean-Atmosphere General Circulation Model (HadCM2) and HadCM3];
- Max-Planck-Institute fur Meteorologie, Germany (ECHAM4);

- National Center for Atmospheric Research (NCAR), United States [Parallel Climate Model (PCM)].

Details of these models, including their resolution in the ocean and atmosphere, and original references, can be found in McAvaney et al. (2001). All of the models include representations of important physical processes in the atmosphere and the ocean, as well as sea ice and land surface processes. Four of the models (CSIRO Mk2, GFDL R30, HadCM2, and ECHAM4) include adjustments of heat and freshwater fluxes at the surface to reduce climate drift in the coupled model simulations. The other two models (HadCM3 and PCM) have no flux adjustments and maintain stable global-mean climates when external forcings are not varied. Maximum and minimum temperature and diurnal temperature range data were not available from HadCM3, and the GFDL model does not include a diurnal cycle of solar radiation.

The constant external forcing simulations ("control" runs) represent the natural internal variability of the unforced climate system. We also analyzed simulations with changes in anthropogenic forcing, including changing atmospheric concentrations of greenhouse gases, ozone, and sulfate aerosols, to represent the human influence on climate (GS) and simulations with changes in natural external forcing, including changing solar irradiance and volcanic aerosol amounts in the stratosphere, to represent the climate response to natural external forcings (NAT). A summary of the simulations with the different models and the different forcings is given in Table 1.

\section{Comparison of model simulations with observations}

The observed variability of the detrended Australian-average temperatures on interannual and decadal time scales is compared with the variability in model control runs in Table 2 to evaluate the quality of the simulations of natural internal climate variability. Simple linear detrending was used to attempt to remove any possible anthropogenic signal in the observed indices. The results are insensitive to the order of the polynomial trend removed from the data. After detrending, the observed temperature variations may still include any response to variations of natural or anthropogenic external forcing on time scales less than a century. The standard deviations of the temperatures are used as a measure of the variability. On interannual time scales, the models show generally greater variability than observed for maximum temperature, mean temperature, and DTR and smaller variability for minimum temperatures (Table 2a). This is consistent with reviews by Bell et al. (2000) and Giorgi et al. (2001), which note that simulations with climate models gen- 
TABLE 1. Summary of the climate model simulations used in this analysis, including the length of the control runs available, the different anthropogenic and natural external forcings, and the number of members in the anthropogenic and natural forcing ensembles. For the GFDL model, simulations with natural external forcing alone were not available, so the NAT response was estimated from the difference between model simulations with both anthropogenic forcing and natural external forcing combined (ALL) and simulations with anthropogenic forcing alone, that is, NAT response $\sim(\mathrm{GS}+\mathrm{NAT})$ response - GS response. For the HadCM2 model, only simulations with separate solar (SOL) and volcanic (VOL) forcing were available, so the NAT response was estimated as the sum of these model responses, that is, NAT response $\sim$ SOL response + VOL response. Descriptions of the forced simulations with the different models include CSIRO (Watterson and Dix 2003), ECHAM4 (Roeckner et al. 1999), GFDL (Broccoli et al. 2003; Delworth et al. 2002), HadCM2 (Tett et al. 1999), HadCM3 (Stott et al. 2000), and PCM (Meehl et al. 2003).

\begin{tabular}{|c|c|c|c|c|c|c|}
\hline Model & Control (yr) & $\begin{array}{l}\text { Greenhouse } \\
\text { forcing }(G)\end{array}$ & $\begin{array}{l}\text { Sulfate aerosol } \\
\text { forcing }(S)\end{array}$ & Natural forcing & $\begin{array}{l}\text { Anthropogenic } \\
\text { ensemble }\end{array}$ & Natural ensemble \\
\hline CSIRO Mk2 & 945 & $\begin{array}{l}\text { Equivalent } \\
\mathrm{CO}_{2}\end{array}$ & Surface albedo changes & Not available & GS, 7 members & Not available \\
\hline $\begin{array}{l}\text { ECHAM4/ } \\
\text { OPYC3 }\end{array}$ & 240 & $\begin{array}{l}\text { Individual } \\
\text { gases }\end{array}$ & $\begin{array}{l}\text { Interactive sulfur scheme } \\
\text { with prescribed sources, } \\
\text { direct and first indirect } \\
\text { effect }\end{array}$ & Not available & $\begin{array}{l}\text { GS + ozone, } \\
2 \text { members }\end{array}$ & Not available \\
\hline GFDL R30c & $\begin{array}{r}\text { 900, no } \\
\text { DTR }\end{array}$ & $\begin{array}{l}\text { Equivalent } \\
\mathrm{CO}_{2}\end{array}$ & Surface albedo changes & $\begin{array}{l}\text { SOL: Lean (2000) } \\
\text { VOL: Andronova } \\
\text { et al. (1999) }\end{array}$ & GS, 3 members & $\begin{array}{r}\text { ALL-GS, } 3 \\
\text { members }\end{array}$ \\
\hline Had CM2 & 240 & $\begin{array}{l}\text { Equivalent } \\
\mathrm{CO}_{2}\end{array}$ & Surface albedo changes & $\begin{array}{l}\text { SOL: Lean et al. } \\
\quad(1995) \\
\text { VOL: Sato et al. } \\
(1993)\end{array}$ & GS, 4 members & $\begin{array}{l}\mathrm{VOL}+\mathrm{SOL}, 3 \\
\text { members }\end{array}$ \\
\hline HadCM3 & $\begin{array}{l}\text { 1250, no } \\
\text { DTR }\end{array}$ & $\begin{array}{l}\text { Individual } \\
\text { gases }\end{array}$ & $\begin{array}{l}\text { Interactive sulfur scheme } \\
\text { with prescribed sources, } \\
\text { direct and first indirect } \\
\text { effect }\end{array}$ & $\begin{array}{l}\text { SOL: Lean et al. } \\
\text { (1995) } \\
\text { VOL: Sato et al. } \\
\text { (1993) }\end{array}$ & $\begin{array}{l}\text { GS + ozone, } \\
4 \text { members }\end{array}$ & NAT, 4 members \\
\hline $\begin{array}{l}\text { NCAR-DOE } \\
\text { PCM }\end{array}$ & 810 & $\begin{array}{l}\text { Individual } \\
\text { gases }\end{array}$ & $\begin{array}{l}\text { Historical sulfate aerosol } \\
\text { amounts, direct effect }\end{array}$ & $\begin{array}{l}\text { SOL: Hoyt and } \\
\text { Schatten (1993) } \\
\text { VOL: Ammann et } \\
\text { al. (2003) }\end{array}$ & $\begin{array}{r}\text { GS + ozone } \\
4 \text { members }\end{array}$ & NAT, 3 members \\
\hline
\end{tabular}

erally overestimate the variability of mean temperatures over continents. On decadal time scales, the simulations agree better with the observations, and there are no significant differences between the models and the observed decadal variability of mean temperature (Table 2b). However, most of the models still overestimate the decadal variability of maximum temperature and DTR, and underestimate minimum temperature variability.

The relationship between Australian-average DTR and mean, maximum, and minimum temperature variations is assessed in Table 3, which shows the correlations between interannual variations. The observed correlation between DTR and mean temperature is

TABLE 2. Standard deviations of variations of Australian area-average temperatures $\left({ }^{\circ} \mathrm{C}\right)$ from observations and model control runs. The observational data had a simple linear trend removed prior to calculating the standard deviation. The uncertainties on the model values are the $90 \%$ confidence intervals for the standard deviation, estimated by resampling the long control runs. Results are for (a) annual mean data and (b) low-pass-filtered data with variations on decadal and longer time scales.

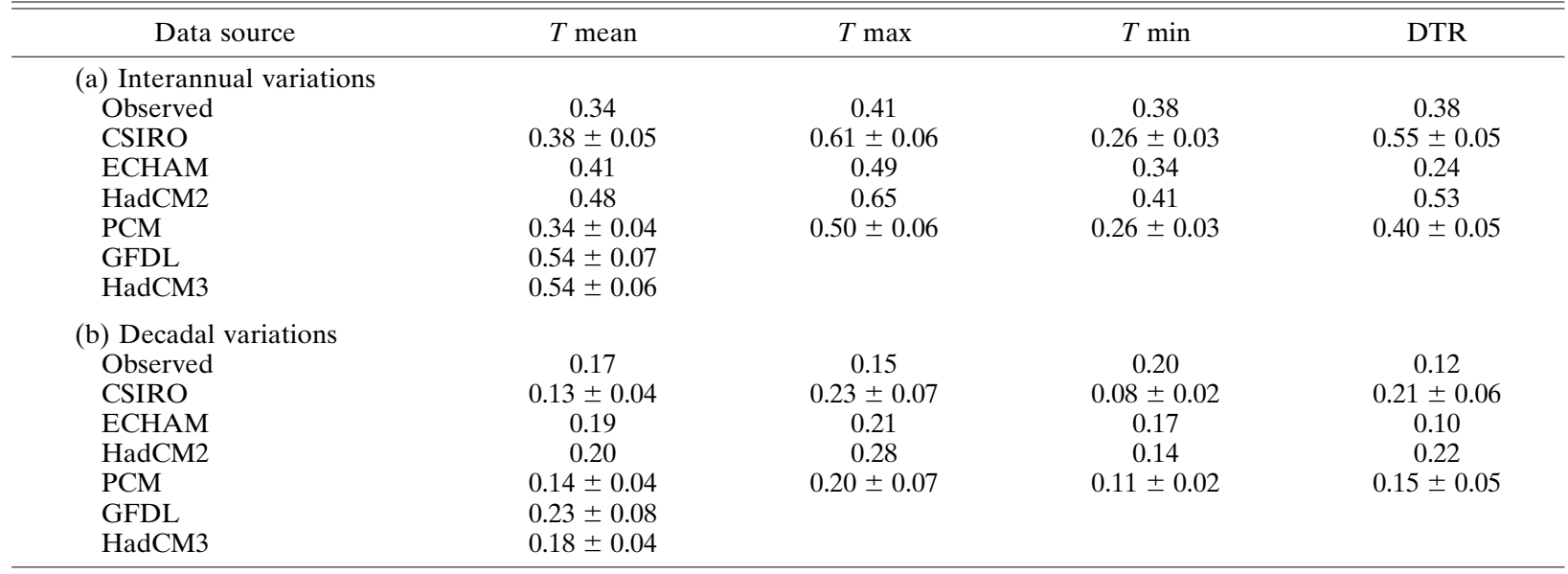


TABLE 3. Correlations of interannual variations of Australian area-average temperatures with diurnal temperature range from observations and control model simulations. The observational data had a simple linear trend removed, prior to calculating the correlation. The uncertainties on the model values are the $90 \%$ confidence intervals for the correlation, estimated by resampling the long control runs.

\begin{tabular}{lccc}
\hline \hline Data source & $T$ mean & $T$ max & $T$ min \\
\hline Observed & 0.08 & 0.53 & -0.42 \\
CSIRO & $0.72 \pm 0.08$ & $0.90 \pm 0.03$ & $0.00 \pm 0.20$ \\
ECHAM & 0.65 & 0.77 & 0.40 \\
HadCM2 & 0.51 & 0.78 & -0.06 \\
PCM & $0.65 \pm 0.10$ & $0.86 \pm 0.05$ & $0.09 \pm 0.15$ \\
\hline
\end{tabular}

close to zero, indicating that they are nearly independent for natural climate variations. Observed DTR has a significant positive correlation with maximum temperatures and negative correlation with minimum temperatures, consistent with it being the difference of two variables with similar variance. However, the model simulations do not agree well with the observations for these relationships. All of the models show a significant positive correlation between DTR and mean temperature, associated with too strong a relationship of DTR with maximum temperature and too large variability of maximum temperature. While the models do not simulate well the observed relationship between DTR and mean temperature, they do not underestimate their interannual and decadal variability.

Next, the observed linear trends in the Australianaverage temperatures over the second half of the twentieth century, as well as the whole century, are compared with anthropogenically forced (GS) model simulations in Fig. 1. We use the observed trends starting in 1910 and 1913 to estimate the sensitivity of the 90-yr observed trend to small changes in the initial year and, starting in 1950 and 1953, for the 50-yr trends. The uncertainty in the forced model response is reduced by using the ensemble-mean response for each model (see Table 1 for the number of members in each ensemble). The ensemble mean model trends are used starting in 1910 and 1950, as data from some of the model simulations was not available past 1999. The model trends were not sensitive to the starting date, as they were averaged over the different members of the ensemble, reducing the impact of internal climate variations. The probability distribution of 50- and $90-\mathrm{yr}$ trends due to internal climate variability is estimated from the long control simulations with the CSIRO and PCM models.

Over the period of 1950-99, there were significant increases in the observed Australian area-average mean, maximum, and minimum temperatures (since the observed trends are outside $90 \%$ confidence intervals for natural internal variability, shown in Fig. 1a). The observed trends over 1953-2002 are slightly smaller than over 1950-99 because of cooler Australian temperatures averaged over 2000-02, compared with the previous 3 years. The largest impact is on the DTR trend, which is half of the magnitude of the trend over 1950-99; but, neither are outside the range of natural internal variability. The observed trends in maximum temperature and diurnal temperature range during 1950-99 (or 1953-2002) are consistent with the response to anthropogenic forcing (GS) in all of the models. (By consistent, we mean that the observed trend lies within the $90 \%$ confidence interval obtained by combining the uncertainty for the ensemble-mean forced model trend with the uncertainty for an individual realization estimated from control runs.) However, the CSIRO and PCM model trends for mean and minimum temperature are significantly smaller than observed. The model trends for DTR are consistently smaller than observed, but this difference is not statistically significant.

Over the periods 1910-99 and 1913-2002, there were significant increases in the observed Australian mean, maximum, and minimum temperatures and a significant decrease in the observed diurnal temperature range (Fig. 1b). The observed trends in maximum and mean temperature are consistent with the response to anthropogenic forcing in all of the models. However, the model trends for minimum temperature and DTR are significantly smaller than observed.

A number of studies have indicated a possible contribution from changes in natural external forcings (solar irradiance and volcanic aerosols) to the observed global warming in the first half of the twentieth century (Tett et al. 1999; Stott et al. 2000; Mitchell et al. 2001). In the following, we use four different climate models to investigate whether natural external forcing can explain the observed trends in Australian mean temperature. Maximum and minimum temperature and DTR data were not available from most of the NAT-forced simulations, so this analysis is restricted to mean temperature. Naturally forced simulations were not available for the CSIRO and ECHAM4 models. For both 1950-99 and 1910-99, the observed warming trend over Australia is consistent with the ensemble mean response to anthropogenic forcing from all these models except PCM, which has significantly smaller warming than observed (Fig. 2). Meehl et al. (2003) has noted that PCM has a relatively small climate sensitivity. The observed warming is significantly larger than the ensemble-mean response to natural forcing alone in all the models. There is a very small chance (less than $1 \%$ ) that the observed warming trend over these periods could be explained as an unusual case of large warming due to natural internal variability combined with an unusual warming due to natural forcing very different from the ensemble mean response. These results for the Australian region are the same as from the global studies referred to above.

Time series of low-pass-filtered Australian-average mean temperatures from the ensemble means of the anthropogenically forced model simulations are in good agreement with the observed warming in the second half of the twentieth century, with the PCM model 
(a) Australian temperature trends 1950-99

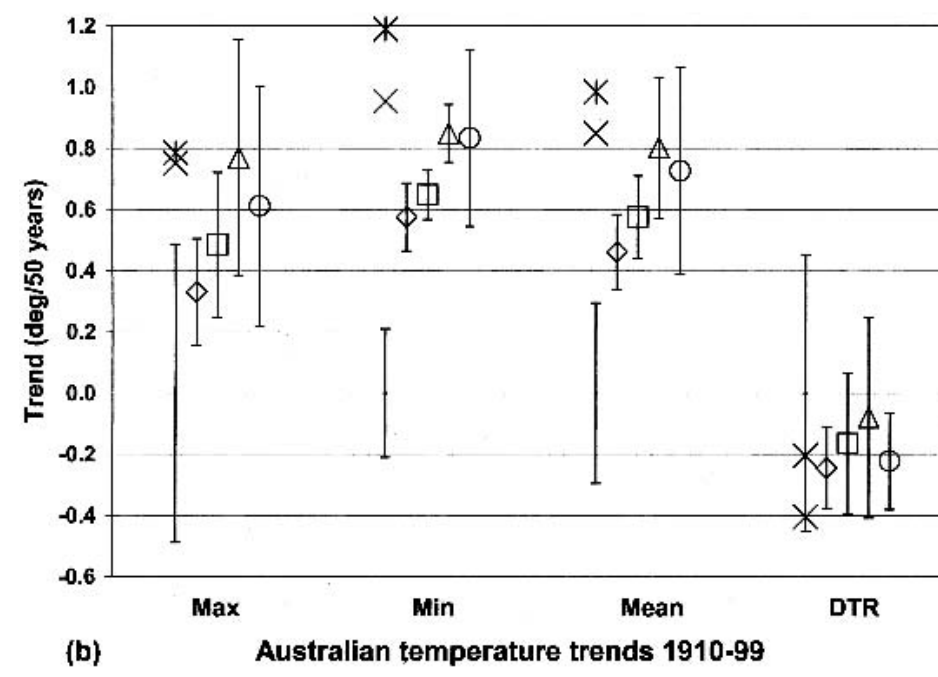

\section{* Obs $\mathbf{5 0 - 9 9}$ \\ $\triangle \mathrm{PCM}$ \\ 口CSIRO \\ $\triangle \mathrm{HadCM} 2$ \\ OECHAM \\ $\times$ Obs 53-02}

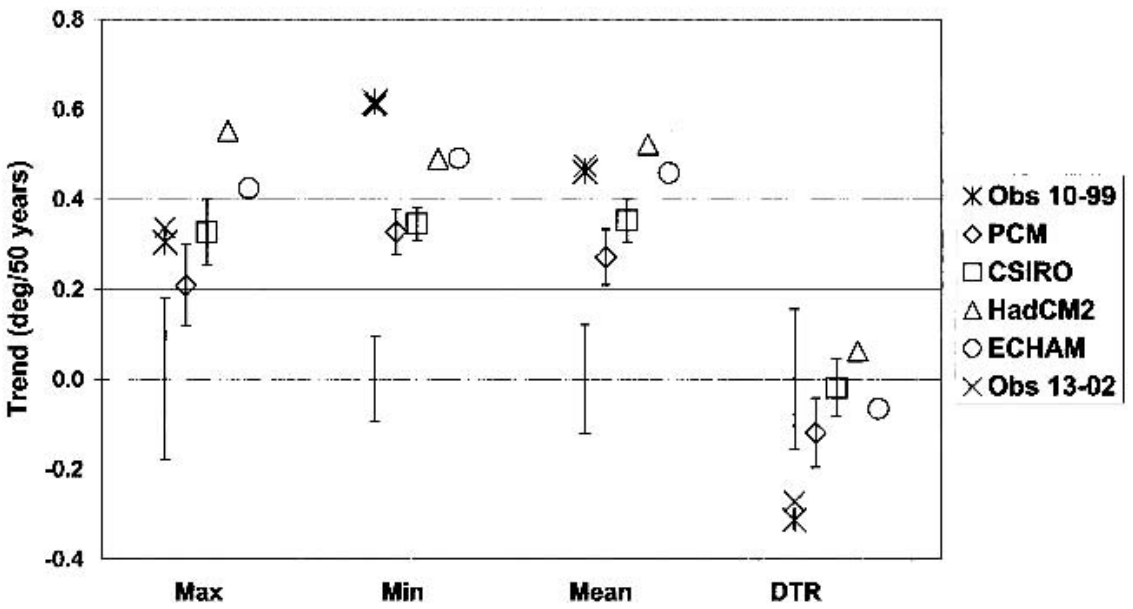

FIG. 1. Trends in Australian area-average temperatures from anthropogenically forced model simulations and observations over (a) 1950-99 and (b) 1910-99. The error bars on the model trends are the $90 \%$ confidence intervals for the ensemble mean trends, estimated by resampling the long control runs from the respective models and allowing for the number of members in each ensemble. No error bars are shown on the HadCM2 and ECHAM 90-yr trends because of the short length of control runs available for this analysis. The error bars about zero at the location of the observed trends are the uncertainties in the trend estimates due to natural internal climate variability, as simulated by the models. They are the $90 \%$ confidence intervals for a single realization, estimated using the control runs from the CSIRO and PCM models, which were the only models with long control runs with DTR data available.

showing less warming (Fig. 3), as expected from the analysis of the trends above. The naturally forced simulations do not show warming in the second half of the century and are clearly separated from the observed temperatures and the anthropogenically forced simulations in the later part of the century.

\section{Discussion}

In summary, we find

- significant observed increases in Australian mean, maximum, and minimum temperatures over the second half of the twentieth century and over the whole century and significant reductions in diurnal temperature range over the whole century

- general agreement between anthropogenically forced (GS) model simulations and the observed changes in the second half of the century and over the whole century, although some models simulate smaller changes than observed

- very small chance that the observed changes can be explained by natural externally forced climate variations, as simulated by these models.

We have confidence in the results as they are very similar for all of the models, despite differences in the 
Australian mean temperature trends

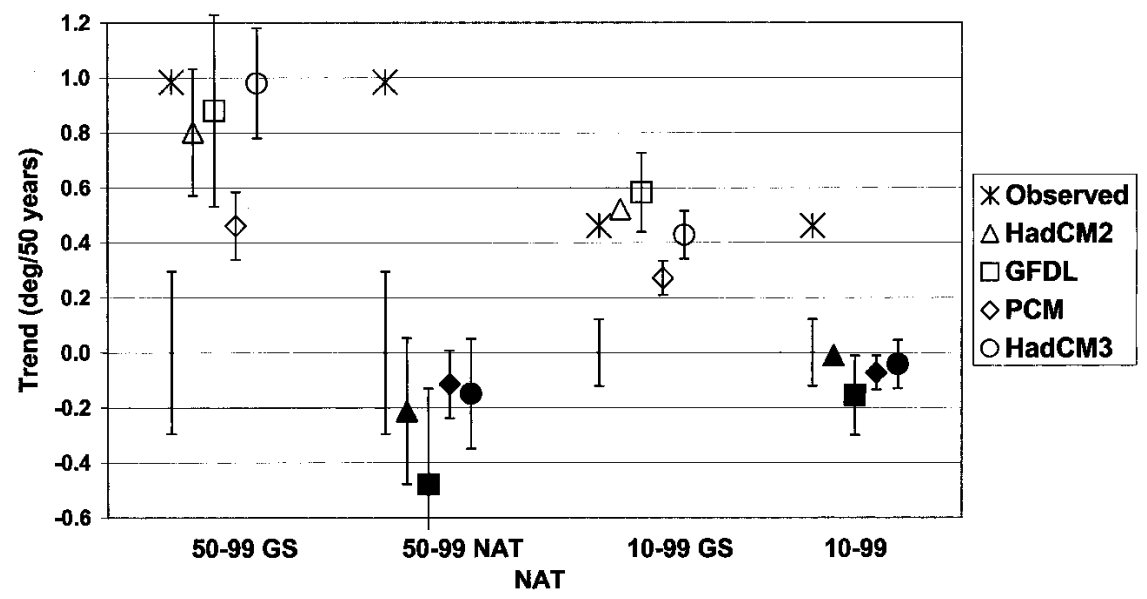

FIG. 2. Trends in Australian-average mean temperature from anthropogenically forced (GS, open symbols) and natural externally forced (NAT, solid symbols) model simulations and observations during 1950-99 and 1910-99. The error bars on the model trends are the $90 \%$ confidence intervals for the ensemble mean trend, estimated by resampling the respective long control runs and allowing for the number of members in each ensemble. The error bars about zero at the location of the observed trends are the uncertainties in the trend estimates due to natural internal climate variability, as simulated by the models. They are the $90 \%$ confidence intervals for a single realization, estimated using the control runs from the CSIRO and PCM models. Results are shown for the HadCM2, GFDL, HadCM3, and PCM models only, as these were the only models with simulations available that included natural external forcing.

\section{Low-pass filtered Australian mean temperatures from observations and forced model simulations}

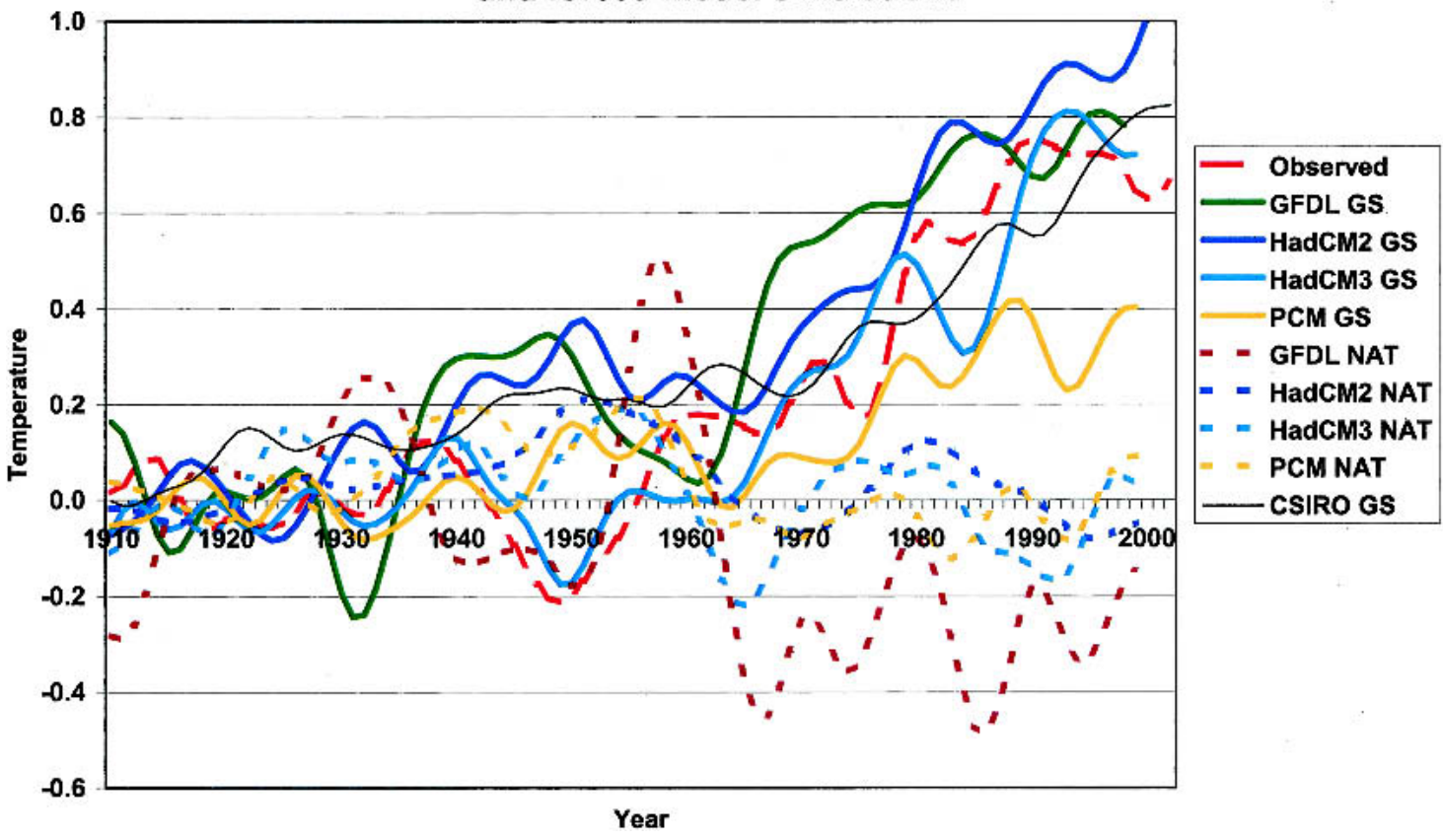

FIG. 3. Time series of low-pass-filtered Australian mean temperature anomalies from observations (red long-dashed line) and ensemble-mean model simulations with variations in anthropogenic forcing (GS, solid lines) or natural external forcing (NAT, short-dashed lines). Simulations that included natural forcing were available only for the GFDL, HadCM2, HadCM3, and PCM models. All the time series have been adjusted to be anomalies relative to a 1910-30 average. 
model formulations and differences in the representations of the anthropogenic and natural forcings. However, we have not considered some other possible anthropogenic forcings, such as changes in land cover or the role of particulates and other nonsulfate aerosols, which are likely to be more important on regional than on global scales. In particular, Narissa and Pitman (2003) have shown that Australian land cover changes may have contributed to the observed increases in maximum temperatures in the southeast and southwest of Australia. However, they found a very small contribution to Australian-average temperature changes due to land cover change.

The PCM model warming due to anthropogenic forcing in the Australian region is slightly smaller than the observed trends and the warming in the other models. The PCM model has a smaller climate sensitivity than most of the other models used and a relatively small global radiative cooling due to anthropogenic aerosols. While these two may compensate globally, in the Australian region there is little radiative cooling due to anthropogenic aerosols, and the small climate sensitivity appears to affect the PCM response relative to the other models.

The models consistently show smaller trends than observed for minimum temperature and for diurnal temperature range. Dai et al. (1999) have noted the relationship between the observed decreases in DTR and increases in cloudiness. In the Australian region, there has been an increase in rainfall over the twentieth century (Nicholls 2003), and it is likely that this has been associated with an increase in cloudiness. It is beyond the scope of this study to identify the causes of the discrepancies between the model and observed trends in DTR, but they may be related to model deficiencies in simulating trends in cloudiness.

Stott (2003) used optimal fingerprint techniques to investigate the causes of regional temperature changes. Figure 1 of Stott (2003) shows that the regressionscaling factor, $\beta$ used to determine amplitude consistency in the magnitude of simulated and observed signals was consistent with unity for the Australian region. While it would be possible to attribute Australian temperature changes to anthropogenic forcing based on that result, it was found to be less than conclusive since $\beta$ was smaller and farther from unity than for other regions. The results presented here show more conclusively that Australian area-average temperatures can be attributed to changes in anthropogenic forcing. The main difference between our results and those of Stott (2003) appear to arise from the small differences in the observational datasets used, with the more recent $\mathrm{Bu}$ reau of Meteorology quality-controlled data showing slightly cooler Australian-mean temperatures early in the twentieth century.

Based on the results presented above, it is likely that there has been a significant human influence on the observed Australian warming in the second half of the twentieth century, associated with increasing atmospheric concentrations of greenhouse gases and sulfate aerosols. In addition, the response to changes in natural external forcing is not important for explaining the observed warming trend.

Acknowledgments. We wish to acknowledge the assistance of the many scientists who developed the observational dataset and the climate models used in this study. In particular, we wish to acknowledge the assistance of Julie Arblaster (NCAR), Martin Dix (CSIRO), Tony Hirst (CSIRO), Peter Stott (Hadley Centre), and Ron Stouffer (GFDL) in providing model data for the Australian region. Data from the ECHAM4 simulations were obtained from the IPCC Data Distribution Centre. KB was supported by a discovery grant from the Australian Research Council.

\section{REFERENCES}

Ammann, C. M., G. A. Meehl, W. M. Washington, and C. S. Zender, 2003: A monthly and latitudinally varying volcanic forcing dataset in simulations of 20th century climate. Geophys. Res. Lett., 30, 1657, doi:10.1029/2003GL016875.

Andronova, N. G., E. V. Rozanov, F. Yang, M. E. Schlesinger, and G. L. Stenchikov, 1999: Radiative forcing by volcanic aerosols from 1850 to 1994. J. Geophys. Res., 104, $16807-$ 16826.

Bell, J., P. B. Duffy, C. Covey, and L. Sloan, 2000: Comparison of temperature variability in observations and sixteen climate model simulations. Geophys. Res. Lett., 27, 261-264.

Broccoli, A. J., K. W. Dixon, T. L. Delworth, T. R. Knutson, and R. J. Stouffer, 2003: Twentieth-century temperature and precipitation trends in ensemble climate simulations including natural and anthropogenic forcing. J. Geophys. Res., 108, 4798, doi:10.1029/2003JD003812.

Dai, A., K. E. Trenberth, and T. R. Karl, 1999: Effects of clouds, soil moisture, precipitation, and water vapor on diurnal temperature range. J. Climate, 12, 2451-2473.

Della-Marta, P. M., D. A. Collins, and K. Braganza, 2004: Updating Australia's high-quality annual temperature dataset. Aust. Meteor. Mag., 53, 75-93.

Delworth, T. L., R. J. Stouffer, K. W. Dixon, M. J. Spelman, T. R. Knutson, A. J. Broccoli, P. J. Kushner, and R. T. Wetherald, 2002: Review of simulations of climate variability and change with the GFDL R30 coupled climate model. Climate Dyn., 19, 555-574.

Giorgi, F., and Coauthors, 2001: Regional climate informationEvaluation and projections. Climate Change 2001: The Scientific Basis, J. T. Houghton et al., Eds., Cambridge University Press, 583-638.

Hoyt, D. V., and K. H. Schatten, 1993: A discussion of plausible solar irradiance variations, 1700-1992. J. Geophys. Res., 98, 18 895-18 906.

Jones, P. D., M. New, D. E. Parker, S. Martin, and I. G. Rigor, 1999: Surface air temperature and its variations over the last 150 years. Rev. Geophys., 37, 173-199.

Karoly, D. J., K. Braganza, P. A. Stott, J. M. Arblaster, G. A. Meehl, A. J. Broccoli, and K. W. Dixon, 2003: Detection of a human influence on North American climate. Science, 302, 1200-1203.

Lean, J., 2000: Evolution of the sun's spectral irradiance since the Maunder minimum. Geophys. Res. Lett., 27, 2425-2428.

, J. Beer, and R. Bradley, 1995: Reconstruction of solar irradiance since 1610: Implications for climate change. Geophys. Res. Lett., 22, 3195-3198. 
McAvaney, B. J., and Coauthors, 2001: Model evaluation. Climate Change 2001: The Scientific Basis, J. T. Houghton et al., Eds., Cambridge University Press, 471-523.

Meehl, G. A., W. M. Washington, T. M. L. Wigley, J. M. Arblaster, and A. Dai, 2003: Solar and greenhouse gas forcing and climate response in the twentieth century. J. Climate, 16, 426-444.

Mitchell, J. F. B., D. J. Karoly, M. R. Allen, G. Hegerl, F. Zwiers, and J. Marengo, 2001: Detection of climate change and attribution of causes. Climate Change 2001: The Scientific Basis, J. T. Houghton et al., Eds., Cambridge University Press, 695738.

Narissa, G. T., and A. J. Pitman, 2003: The impact of 200 years of land cover change on the Australian near-surface climate. $J$. Hydrometeor., 4, 424-436.

Nicholls, N., 2003: Continued anomalous warming in Australia. Geophys. Res. Lett., 30, 1370, doi:10.1029/2003GL017037.

Plummer, N., Z. Lin, and S. Torok, 1995: Trends in the diurnal temperature range over Australia since 1951. Atmos. Res., 37, 79-86.

Roeckner, E., L. Bengtsson, J. Feichter, J. Lelieveld, and H. Rodhe, 1999: Transient climate change simulations with a coupled ocean-atmosphere GCM including the tropospheric sulfur cycle. J. Climate, 12, 3004-3032.

Sato, M., J. E. Hansen, M. P. McCormick, and J. Pollack, 1993:
Stratospheric aerosol optical depths (1850-1990). J. Geophys. Res., 98, 22 987-22 994.

Stott, P. A., 2003: Attribution of regional-scale temperature changes to anthropogenic and natural causes. Geophys. Res. Lett., 30, 1728, doi:10.1029/2003GL017324.

- and S. F. B. Tett, 1998: Scale-dependent detection of climate change. J. Climate, 11, 3282-3294.

$\longrightarrow$, G. S. Jones, M. R. Allen, J. F. B. Mitchell, and G. J. Jenkins, 2000: External control of 20th century temperature by natural and anthropogenic forcings. Science, 290, 2133 2137.

Tett, S. F. B., P. A. Stott, M. R. Allen, W. J. Ingram, and J. F. B. Mitchell, 1999: Causes of twentieth-century temperature change near the Earth's surface. Nature, 399, 569-572.

Torok, S. J., and N. Nicholls, 1996: An historical annual temperature data set for Australia. Aust. Meteor. Mag., 45, 251-260.

Watson, R. T., and the Core Writing Team, Eds., 2001: Climate Change 2001: Synthesis Report. Cambridge University Press, $398 \mathrm{pp}$

Watterson, I. G., and M. R. Dix, 2003: Simulated changes due to global warming in daily precipitation means and extremes and their interpretation using the gamma distribution. J. Geophys. Res., 108, 4379, doi:10.1029/2002JD002928.

Zwiers, F. W., and X. Zhang, 2003: Toward regional-scale climate change detection. J. Climate, 16, 793-797. 